\title{
Comparison between emissions from the pyrolysis and combustion of different wastes
}

\author{
J.A. Conesa, R. Font*, A. Fullana, I. Martín-Gullón, I. Aracil, A. Gálvez, J. Moltó, M.F. Gómez-Rico \\ Chemical Engineering Department, University of Alicante, P.O. Box 99, 03080 Alicante, Spain
}

\section{A R T I C L E I N F O}

\section{Article history:}

Received 30 June 2008

Accepted 13 November 2008

Available online $\mathrm{xxx}$

\section{Keywords:}

Wastes

Pyrolysis

Combustion

PCDD/Fs

PAHs

\begin{abstract}
A B S T R A C T
A comparison between different emission rates of various pollutants obtained from various wastes is presented. The studied wastes were the following: polyethylene (PE), tyres, sewage sludges, polyvinyl chloride (PVC), cotton textiles, polyester textiles, meat and bone meals (MBMs), varnish wastes, olive oil solid waste (pomace), waste lube oils and paper waste. The decomposition of these wastes was studied in a horizontal laboratory scale reactor under fuel-rich conditions, and the analysis of the pollutants evolved comprised several compounds such as light hydrocarbons, polyaromatic hydrocarbons (PAHs) and polychlorinated dibenzo- $p$-dioxins and dibenzofurans ( $\mathrm{PCDD} / \mathrm{Fs}$ ).

From the studied wastes, a general behaviour was deduced regarding the evolution of semi-volatile compounds with the increase of temperature, both in pyrolysis and combustion. The results showed that the emissions of some compounds decreased with increasing oxygen ratio. Compounds with this behaviour were mainly volatile hydrocarbons, which were consumed in presence of oxygen. In addition, compounds with oxidized structure were present a maximum with oxygen ratio. Intermediate compounds with very high resistance to the oxygen under the working conditions increased continuously in concentration when the oxygen ratio increased.

With reference to behaviour versus temperature there were compounds whose yields decreased with increasing temperature, such as volatile hydrocarbons and semi-volatile compounds. Also some pollutants are promoted at intermediate temperatures, e.g. light hydrocarbons, semi-volatile compounds, many monoaromatic compounds and many polyaromatic hydrocarbons.
\end{abstract}

(c) 2008 Elsevier B.V. All rights reserved.

\section{Introduction}

Pyrolysis and combustion have always been considered as attractive alternatives for waste disposal, since these techniques provide a reduction in volume of waste and also involve profitable energetic and/or chemical products.

Thermal decomposition of waste can take place both in controlled conditions (incinerators, cement kilns ...) and noncontrolled conditions, for example, during fires or open-air burning. The substances emitted during non-controlled plastic thermal degradation may create a serious hazard for human health and for the environment [1].

Since 1984, the Department of Chemical Engineering at the University of Alicante has been working on different research projects involving the pyrolysis of organic wastes such as polyethylene (PE), tyres, sewage sludge, polyvinyl chloride (PVC), paper waste, cotton textiles, polyester textiles, meat and bone meal (MBM), polyurethane-based varnish, orujillo (olive

\footnotetext{
* Corresponding author. Tel.: +34 9659035 46; fax: +34 965903826 .

E-mail address: rafael.font@ua.es (R. Font).
}

pomace) and waste lube oils. These wastes were first of all studied from a kinetic point of view by using a thermobalance, which was not the aim of the present work. The pollutants emitted in different experimental conditions have also been studied [2-16]. In this latter case, the appliance used was a quartz tube that was placed inside a horizontal furnace, which has been described elsewhere [16]. The atmospheres used were both $\mathrm{N}_{2}$ and synthetic air in order to simulate pyrolysis and combustion conditions, respectively. The temperatures of the runs were in the range $500-1100{ }^{\circ} \mathrm{C}$.

In this paper, a comparison between different compounds obtained from pyrolysis and combustion of different wastes is presented. The aim of the present work was to compare the pollutants evolved in the decomposition of different wastes, in order to detect similar behaviours between different pollutants, especially polyaromatic hydrocarbons (PAHs) and polychlorinated dibenzo-p-dioxins and dibenzofurans (PCDD/Fs).

\section{Experimental}

Table 1 shows the elemental analysis and net calorific value for the studied wastes. The final CHNS analysis was carried out in a Perkin Elmer 2400 (Perkin Elmer, UK). The calorific values were 
Table 1

Elemental analysis and calorific value of the studied wastes.

\begin{tabular}{lllrlcc}
\hline Percentage weight) & N & C & H & S & Ash & $\begin{array}{l}\text { Net calorific } \\
\text { value (kcal/kg) }\end{array}$ \\
\hline Pomace & 1.14 & 47.1 & 5.7 & 0.5 & 7.8 & 4260 \\
Polyethylene & - & 85.3 & 14.7 & - & - & 10273 \\
Tyre & 0.39 & 83.5 & 7.8 & 1.5 & 7.3 & 8500 \\
Lube oils & 0.99 & 85.3 & 13.2 & 0.5 & 0.05 & 11524 \\
MBM & 7.80 & 40.4 & 6.4 & 0.5 & 28.7 & 4067 \\
Sludge A & 1.40 & 29.6 & 4.7 & 1.0 & 26.2 & 3710 \\
Sludge B & 7.7 & 42.2 & 6.5 & 0.8 & 14.8 & 4193 \\
PVC & - & 38.4 & 4.8 & 1.4 & - & - \\
Cotton & 0.30 & 45.5 & 6.6 & $<0.1$ & $<0.1$ & 4090 \\
Polyester & 0.40 & 62.6 & 4.6 & $<0.1$ & $<0.1$ & 5470 \\
Varnish & 3.31 & 64.0 & 7.2 & - & 8.0 & 6043 \\
Paper waste & 0.4 & 27.0 & 3.3 & 0.2 & 43.0 & 2249 \\
\hline
\end{tabular}

obtained using an AC-350 calorimetric bomb (Leco Corporation, Michigan, USA). The ash content was obtained by calcination at $850{ }^{\circ} \mathrm{C}$. The main properties of the materials used were the following:

- High density polyethylene (HDPE 10062E) from Dow Plastics: analysis with a Setaram TG-DSC at $15{ }^{\circ} \mathrm{C} / \mathrm{min}$ both in He and $\mathrm{He}: \mathrm{O}_{2} 4: 1$, showed that decomposition takes place in the 440$500{ }^{\circ} \mathrm{C}$ range, and the amount of solid residue is negligible $[2,3]$.

- PVC resin Etinox-450 free of additives obtained by emulsion polymerization: had a medium molecular weight (104,000 and 40,000 for Mw and Mn, respectively) and very small particle size, ranging from 1.4 to $24.4 \mu \mathrm{m}$ [4].

- Meat and bone meal, obtained from a cement plant owned by the CEMEX group: the plant requires 15 ton/h of coke and approximately $10 \%$ is replaced by MBM materials [5].

- Sewage sludge from wastewater: sewage sludge A was obtained from a wastewater plant sited in Catalonia (Spain) [13], which had high concentration of metals, especially iron, and cannot be used as fertilizer. Therefore, the most probable use is in an incinerator [6]. Sewage sludge B came from a rural, industrial zone of Alicante (Spain) and had low content of transition metals [17]. The sewage sludge samples were dried and ground into fine particles before use in this study.

- Waste lubricant oil was collected from a tank in a local garage: all experiments were done with as-received waste oil (non-filtered) $[7,15]$.

- Cotton fabric, a used blue T-shirt made of $100 \%$ cotton represented the used cotton fabric source: the T-shirt was cut into small pieces with an average size of 1 by $1 \mathrm{~cm} \mathrm{[8].}$

- Polyester fabric, a pair of used black shorts made of $100 \%$ polyester represented used polyester fabric: the shorts were cut into small pieces with an average size of 1 by $1 \mathrm{~cm}$ [9].

- Tyre (Dunlop SP Le Mans): was shredded into small pieces with a mean diameter of $5 \mathrm{~mm}$. These pieces which were then immersed in liquid nitrogen, and grounded to a diameter smaller than $1 \mathrm{~mm}$ [10].

- The olive pomace (supplied by "Espuny Castellar", a solid cake extraction company): solid residues from olive oil factories which are basically a biomass formed by lignin, cellulose and hemicellulose. The pomace was extracted for the oil traces, the form in which it is usually used for co-firing or combustion alone. It has a relatively low moister content, $7.93 \% \mathrm{wt}$. The residue was not homogeneous; the olive pits were easy to detect amongst the dried pulp [11].

- Varnish waste, obtained from the furniture industry: furniture wastes impregnated with varnish mainly composed of polyurethane and zinc stearate. Polyurethane-based varnish is an association of two components: a 'base resin' and a 'catalyst', which are a polyol and a polyisocyanate, respectively [12].

- Paper waste, the final sludge of the recycling process: $80 \%$ of the paper is recycled but $20 \%$ is a sludge composed mainly by cellulose, kaolin and calcium carbonate. This waste was dried before use [14].

A batch laboratory scale horizontal tubular reactor was used for the continuous simulation of pyrolysis and combustion at fuel-rich conditions (Fig. 1). Basically, 0.1-0.2 g of waste, placed in a quartz crucible, was introduced into the reactor at constant speed $(1 \mathrm{~mm} /$ s) when the furnace had reached the final temperature. The nominal temperature of the runs was varied between 450 and $1050{ }^{\circ} \mathrm{C}$. The solid feeding system consisted of a magnetic system moved by a small engine. The carrier gas (nitrogen for pyrolysis and synthetic air for combustion) was introduced parallel to the waste solid, at a constant flow around $300 \mathrm{~mL} / \mathrm{min}$. At this flow rate, the gas residence time at maximum temperature varied from $7 \mathrm{~s}\left(\right.$ at $450{ }^{\circ} \mathrm{C}$ ) to $3 \mathrm{~s}\left(\right.$ at $1050{ }^{\circ} \mathrm{C}$ ) approximately. After collecting the exit gas for $5 \mathrm{~min}$, the holder was removed from the furnace. More details regarding the experimental procedure can be found elsewhere [2-16].

After passing through the furnace, the reactor gas was collected in an adsorptive trap containing XAD-2 resin (Supelco, Bellefonte, USA). In order to avoid the adsorption of benzene and toluene in the XAD-2 resin, the analyses of the gas fraction and the semivolatile compounds were carried out in two different experiments. The non-condensable gases were collected in a 2 L-Tedlar bag.

The gas fraction was analysed by gas chromatography: quantification of $\mathrm{CO}_{2}$ and $\mathrm{CO}$ with GC-TCD (Shimadzu GC-14A) and light hydrocarbons $C_{1}-C_{6}$ together with benzene and toluene with GC-FID (Shimadzu GC-17A). A total of six different gas standards containing known amounts of hydrocarbons $\mathrm{C}_{1}-\mathrm{C}_{6}, \mathrm{CO}_{2}$ and $\mathrm{CO}$, with the balance completed with $\mathrm{N}_{2}$, were used to calibrate the gas chromatographs.

After each experiment, the resin was extracted with dichloromethane in accordance with the EP3540C EPA method [18], and the extract was analysed using different GC-MS techniques, as this study involves analysis of different groups of compounds.

For the PAH analysis, the following standards (Dr. EhrenstorferSchäfers, Augsburg, Germany) were used: naphthalene, acenaphthylene, acenaphthene, fluorene, phenanthrene, anthracene, fluoranthene, pyrene, benzo(a)anthracene, chrysene, benzo(b)fluoranthene, benzo(k)fluoranthene, benzo(a)pyrene, dibenzo(a,$\mathrm{h}$ )anthracene, benzo(g,h,i)perylene, indeno[1,2,3-cd]pyrene. Six deuterated compounds (Dr. Ehrenstorfer-Schäfers, Augsburg,

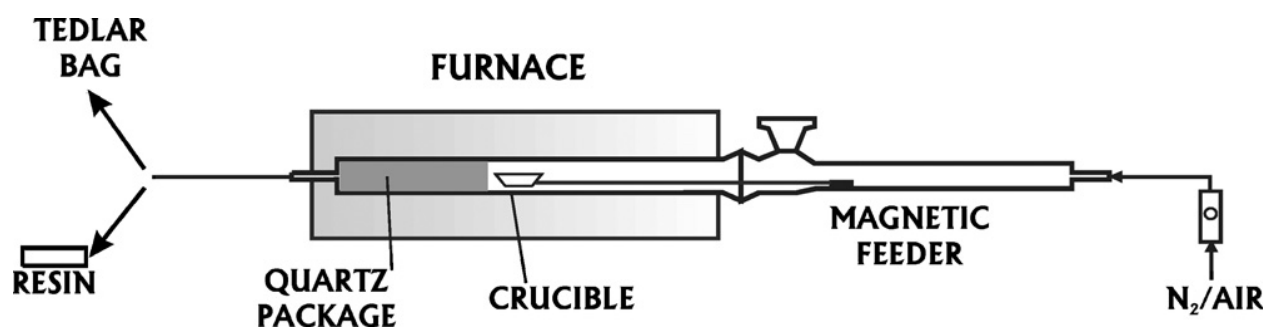

Fig. 1. Schematic figure of the batch laboratory scale tubular reactor. 
Germany) were used as internal standards: 1,4-dichlorobenzene$d_{4}$, acenaphthene- $d_{10}$, chrysene- $d_{12}$, naphthalene- $d_{8}$, perylene$d_{12}$, phenanthrene- $d_{10}$. The deuterated standards were added to the solvent at the beginning of the extracting process. In accordance with the EP8270C EPA method [13], the response factors of the non-determined compounds were calculated with the response factor of the standard with the nearest retention time.

The PCDD/F analysis was carried out by high resolution gas chromatography coupled to a high resolution mass spectrometer (HRGC/HRMS). For HRGC, an Agilent HP5890 gas chromatograph equipped with a PTV inlet with septumless head was used. For HRMS, a Micromass Autospec Ultima NT mass spectrometer (Micromass, Waters, UK) with a positive electron impact (EI+) source was employed. The analytical procedure comprises the extraction with toluene, change of solvent to hexane, acid treatment with sulphuric acid and cleanup using the Power PrepTM system (FMS Inc., MA, USA) with three different columns: silica, alumina and activated carbon (FMS Inc., Boston, USA). ${ }^{13} \mathrm{C}$ labelled compounds included in the EPA 1613 method were used. A blank without sample, using the laboratory scale reactor in the same conditions as the runs, was done before the combustion experiments.

All the solvents (acetone, dichloromethane, toluene, n-hexane and ethyl acetate) for organic trace analysis were purchased from Merck (Germany).

Quality assurance criteria were based on applications of quality control measures such as the analysis of blanks, analysis of certified reference materials and participation in intercalibration exercises. Other performance checks taken into account were accurate isomer-specific GC separation, sensitivity check and 10000 resolution power of HRMS, sufficient recovery and fulfilment of the minimum requirements described in the EPA 1613 method.

\section{Results and discussion}

\subsection{Evolution of yields versus temperature and oxygen ratio}

In order to study the compounds produced during the combustion of different residues, it is useful to use the horizontal furnace described previously (Fig. 1). The use of this furnace enables experiments simulating industrial scale processes of combustion and pyrolysis. An important parameter in combustion processes is the $\mathrm{CO} /\left(\mathrm{CO}+\mathrm{CO}_{2}\right)$ ratio indicating the type of combustion.

The results showed that from the studied wastes, a general behaviour was deduced regarding the evolution of semi-volatiles with increasing temperature, both in pyrolysis and in combustion. The following trends could be found.

\subsubsection{Compounds with decreasing emission with increasing oxygen ratio}

These compounds were formed in pyrolytic conditions, but they were consumed in the presence of oxygen. The following can be mentioned: volatile hydrocarbons (methane, ethane, benzene), semi-volatile aliphatic compounds (1-dodecene, n-pentadecane), monoaromatic hydrocarbons (o-xylene, 1-propenyl benzene) and polyaromatic hydrocarbons (biphenyl, anthracene).

\subsubsection{Compounds presenting a maximum with oxygen ratio}

These were generally partially oxidized compounds (alcohols, organic acids, furans and some amides). Some compounds that do not have oxygen in their structure are also present in this group, but they were most likely formed by decomposition of oxygenated compounds such as aldehydes or ketones. From a toxicological point of view, these compounds are very important, since PCDD/Fs are part of this group (as is the case of benzofurane). In some cases, methane, acetylene, benzene, benzo(a)anthracene and chrysene showed a behaviour corresponding to this group.

\subsubsection{Compounds with a continuous increase in concentration with increasing oxygen ratio}

These were intermediate compounds with very high resistance to oxygen under the working conditions. The following compounds belonged to this group: carbon oxides, volatile hydrocarbons at moderate temperatures (propylene) and some oxygenated compounds (11-docecenal, tridecanal). In more aggressive conditions (higher temperature or residence time) the organic compounds should present a maximum.

With reference to behaviour of yields versus temperature (between 450 and $1050{ }^{\circ} \mathrm{C}$ ) in inert atmosphere (pyrolytic conditions), the cracking reactions involved must be taken into account. High temperatures favor two types of reactions: cracking reactions to form methane, carbon and hydrogen, and also pyrosynthesis reactions (yielding different organic compounds and soot [19]), so these compounds transform into both higher and lower molecular weight compounds. Atal et al. [20] demonstrated that the PAH yield is a consequence of the pyrosynthesis and cracking reactions in a combustion reactor. The following behaviours could be distinguished.

\subsubsection{Compounds with decreasing yields with increasing temperature (pyrolysis)}

Within this group, some volatile hydrocarbons (n-butane) and semi-volatile compounds (1-heneicosene, n-hexadecane, 1 -chlorohexadecane) could be indicated.

\subsubsection{Compounds with a maximum yield versus temperature variation (pyrolysis)}

This group contained light hydrocarbons (ethane, isobutene), semi-volatile compounds (1-dodecene, 1,16-heptadecadiene), many monoaromatic compounds (phenylethyne, m-methylstyrene) and many polyaromatic hydrocarbons (naphthalene, phenanthrene, benzo(a)fluorene, 1- and 2-chloronaphthalene). The results showed that the yields of these compounds reached a maxima at intermediate temperatures $\left(750-850^{\circ} \mathrm{C}\right)$. This was a group that consisted primarily of PAHs having an important thermal stability, increasing their yields at intermediate temperatures since they are products of cracking and pyrosynthesis reactions. When the temperature was high enough, these compounds were transformed into reactants of these types of reactions, then lowering their yields (temperature higher than $850^{\circ} \mathrm{C}$ ).

\subsubsection{Compounds with increasing yields with increasing temperature (pyrolysis)}

Methane, acetylene and in some cases fluoranthene and some chlorinated compounds (1-chloro-3-methylbenzene) belonged to this group. Methane and acetylene were the final products of many cracking reactions and logically their yields increased with temperature. Concerning the other compounds, such as those indicated previously, these can have this apparent behaviour as a consequence of the pyrosynthesis reactions, but in their absence their yields would also decrease.

The behaviour versus temperature in oxidative atmosphere under substoichiometric conditions depends on the temperature interval considered, the oxygen concentration and the residence time. Nevertheless, some general considerations have been deduced for the following behaviours.

\subsubsection{Compounds with decreasing yields with increasing temperature (oxidative atmosphere) \\ Nearly all organic compounds belonged to this group when considering a high temperature interval $\left(750-1100^{\circ} \mathrm{C}\right)$ under}


oxygen deficient conditions not very far from the stoichiometric ones. Durlak and Biswas [21] analysed the PAH production in polystyrene combustion in a vertical furnace; the PAH yield in the gas phase and the particles decreased when increasing the temperature from 800 to $1200{ }^{\circ} \mathrm{C}$. In addition, both the number of different PAH species and the total yields of these compounds decreased. Our results were in agreement with this. Nevertheless, Mastral et al. [22,23] studied the influence of temperature on PAH emissions in a fluidized bed working with carbon. They found that the total PAH yield had a maximum at $800^{\circ} \mathrm{C}$ in their operating conditions, and this result agrees with this type of behaviour, taking into account that formation of PAHs is important above $750-800{ }^{\circ} \mathrm{C}$.

\subsubsection{Compounds with a maximum with a variation of temperature (oxidative atmosphere)}

This group can be formed by some semi-volatile oxygenated compounds (benzoic acid) at intermediate temperature variation $\left(500-800{ }^{\circ} \mathrm{C}\right)$ under slightly substoichiometric conditions.

\subsubsection{Compounds with increasing yields with increasing temperature (oxidative atmosphere)}

In this group some light hydrocarbons (methane, propane), monoaromatic hydrocarbons (phenylethyne, styrene) and PAHs (acenaphthylene, fluorene) were found at very poor oxygen conditions (very far from the stoichiometry).

Bonfanti et al. [24] found a result significantly different from that obtained in the present work when working with carbonaceous materials. The authors observed an increase of PAHs with temperature when working in a Pyroprobe apparatus between 250 and $1000{ }^{\circ} \mathrm{C}$. This behaviour can be due to the fact that the residence time in a Pyroprobe is very low, so cracking reactions do not occur, preventing destruction at the highest temperatures to take place.

\subsection{Comparison of yields from different wastes}

Pyrolysis is an alternative for obtaining chemicals from natural and synthetic polymers. High or significant yields of monomers, methane, ethylene, acetylene and benzene can be obtained from different wastes, depending on the operation temperature and residence time of volatiles. At moderate temperatures (300$500{ }^{\circ} \mathrm{C}$ ), high yields of liquids can be obtained, whereas at high temperatures the gas yield can be very great, close to unity in some cases, with the presence of carbon oxides, methane, ethylene, acetylene, benzene, toluene and other hydrocarbons. Nevertheless, PAHs can also be obtained at high temperatures, and they represent a non-desired pollution. Fig. 2 shows the levels of PAH pollutants for different wastes under pyrolytic conditions at $850^{\circ} \mathrm{C}$. A relatively high yield or emission factor of naphthalene can be observed.

In extremely good combustion conditions, all organics should be oxidized. When the combustion conditions are not so good, some of these organics are obtained, representing the possible pollutants formed in the process. Table 2 shows the yields obtained for the main gases, volatiles and semi-volatiles, and also the total of light hydrocarbons and semi-volatiles for the different studied wastes. Combustion of used oil generated the highest proportion of light hydrocarbons, with an important production of methane, while PVC combustion did not generate light hydrocarbons. For all wastes except for PVC, the sum of the 16 priority PAHs constituted roughly $40 \%$ of the total yield of semi-volatiles. Naphthalene had the highest yield of the PAHs when combusting polyester, sewage sludge and used lube oil.

The amount of each of the analysed compounds formed during the decomposition of each waste was quite diverse. Fig. 3 shows the yield of some compounds found in all wastes (such as methane, benzene, toluene, styrene, naphthalene, acenaphthene, fluorene, phenanthrene, biphenyl and pyrene) and formed from each waste at $850^{\circ} \mathrm{C}$ in poor oxygen atmosphere combustion. Wastes yielding more volatiles were PE, tyres and textile wastes, while other wastes such as sludges, olive pomace and PVC presented lower yields. The presence of oxygen reduces the emissions of a great amount of compounds, which denotes the importance of studying the decomposition in pyrolytic conditions (i.e. conditions where the maximum emissions can be found for most of the compounds). On the other hand and even bearing in mind that industrial incineration systems work in an excess of air, the study at low oxygen relation shows the role that oxygen is playing, and the pollution of the puffs inside the incinerator where there is a defect of oxygen caused by a deficient mixing and/or turbulence.

Table 3 shows the PCDD/Fs levels, expressed in pg I-TEQ/g, of different wastes and the emissions found during combustion and pyrolysis at $850^{\circ} \mathrm{C}$, using the same horizontal reactor described above. Note that the ratio $\mathrm{CO} /\left(\mathrm{CO}+\mathrm{CO}_{2}\right)$ was not the same for all the wastes, although less than unity. Textile and paper wastes did not

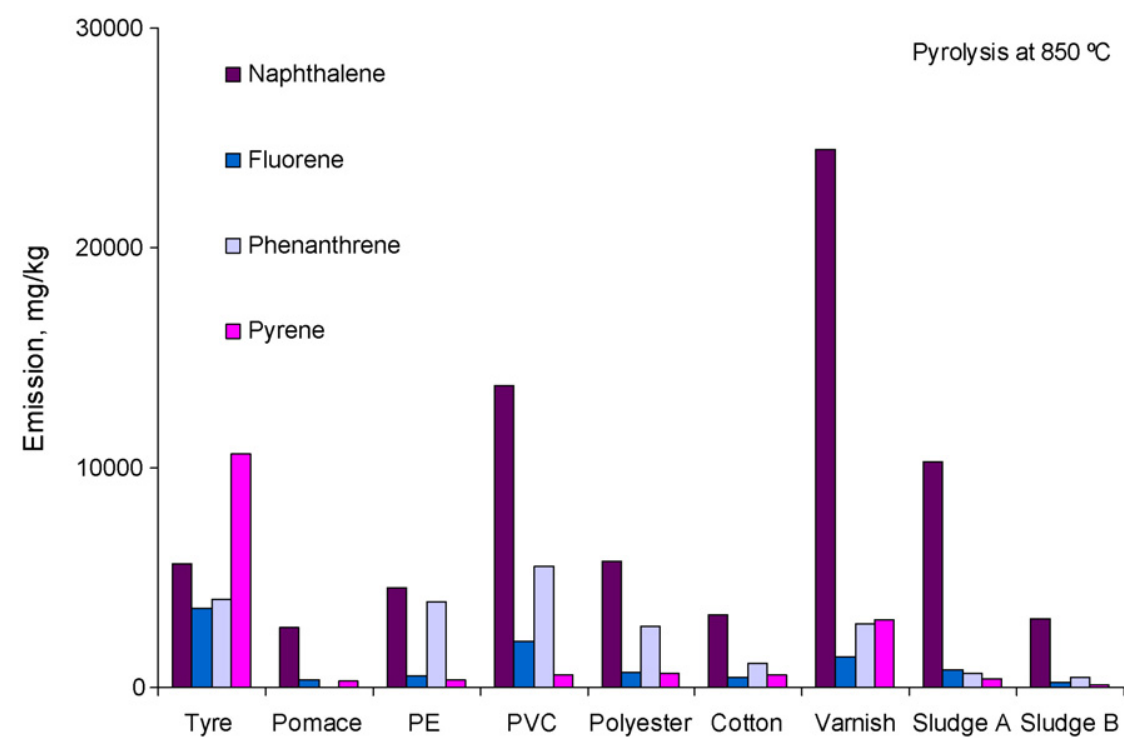

Fig. 2. Emissions of PAHs from pyrolysis at $850{ }^{\circ} \mathrm{C}$ of different wastes. 
Table 2

Comparison of the emissions from combustion at $850^{\circ} \mathrm{C}$ of different wastes.

\begin{tabular}{|c|c|c|c|c|c|c|c|}
\hline & \multicolumn{7}{|c|}{ Combustion at $850^{\circ} \mathrm{C}$ (mg compound/kg sample) } \\
\hline & Pomace & Cotton & Polyester & PVC & Sludge A & Sludge B & Oil \\
\hline $\mathrm{CO} /\left(\mathrm{CO}+\mathrm{CO}_{2}\right)$ & 0.055 & 0.216 & 0.106 & 0.092 & 0.111 & 0.079 & 0.457 \\
\hline \multicolumn{8}{|l|}{ Gases and major volatile compounds } \\
\hline $\mathrm{CO}_{2}$ & 777762 & 997000 & 1451000 & 1308420 & 510000 & 1000000 & 1260000 \\
\hline $\mathrm{CO}$ & 45173 & 275000 & 172500 & 131820 & 64000 & 86000 & 1060000 \\
\hline Methane & 8577 & 34500 & 20100 & nd & 1200 & 17000 & 77400 \\
\hline Ethylene & 8047 & 37500 & 11900 & nd & 31000 & 14000 & 31800 \\
\hline Benzene & 1833 & 9600 & 77600 & nd & 13000 & 6800 & 10600 \\
\hline Percentage (benzene/total light HC) & 8 & 10 & 66 & & 18 & 10 & 8 \\
\hline Ethyne + i-butane & 2392 & 6100 & 1360 & nd & 2600 & 1900 & 2930 \\
\hline Toluene & 320 & 1700 & 3800 & nd & 900 & 860 & 100 \\
\hline Total light HC & 22496 & 98310 & 117740 & 4376 & 73000 & 65000 & 126000 \\
\hline \multicolumn{8}{|l|}{ Semi-volatile compounds } \\
\hline \multicolumn{8}{|l|}{ Major PAHs } \\
\hline Naphthalene & 127 & 530 & 7770 & nd & 2900 & 930 & 1700 \\
\hline Acenaphthene & 123 & 830 & 1320 & nd & 570 & 220 & 280 \\
\hline Fluorene & 24 & 300 & 1240 & nd & 310 & 39 & 10 \\
\hline Phenanthrene & nd & 530 & 4190 & nd & 166 & 150 & 330 \\
\hline Total 16 PAHs & 598 & 3415 & 16630 & nd & 4638 & 1490 & 2850 \\
\hline Percentage (16 PAHs/total semi-volatiles) & 45 & 40 & 44 & nd & 39 & 23 & 50 \\
\hline \multicolumn{8}{|l|}{ Other important semi-volatiles } \\
\hline Styrene & 193 & 2240 & nd & nd & 3600 & - & nd \\
\hline Biphenyl & nd & 150 & 12930 & nd & 120 & 91 & 80 \\
\hline Benzoic acid & nd & nd & nd & 6061 & nd & - & 40 \\
\hline Phenol & nd & 170 & nd & 9 & 190 & - & 560 \\
\hline Total semi-volatile compounds & 1329 & 8608 & 37410 & 6420 & 12000 & 6460 & 5710 \\
\hline
\end{tabular}

show a great change in the levels of PCDD/Fs generated in the waste combustion compared to the PCDD/F content in the waste itself, whereas in the other materials, combustion generated a considerable amount of dioxins and furans. This is presumably related to the amount of chlorine and/or metals that the waste contained [25-27]. For a waste containing low amounts of organic chlorine, production of chlorinated compounds was obviously limited in the experimental apparatus used in the present work. However, the presence of certain metals increased the amount of some compounds generated in postcombustion reactions [27]. This could be observed comparing the emission levels of dioxins between sludge $A$, with a high content of iron, and sludge $\mathrm{B}$, with a lower content.
The evaluation of PCDD/F emissions in the Spanish cement sector during the period 2000-2003 [28] showed that the use of waste as fuel did not influence the emission of PCDD/Fs. The incorporation of such fuels only influenced the emission profile which depends on the waste used; mixtures and the characteristics of each installation.

Fig. 4 shows the relative profile of congeners found (in pg I-TEQ/ $\mathrm{g}$ ) in the combustion at $850{ }^{\circ} \mathrm{C}$ of some of the studied wastes. There was no characteristic profile for the combustion, and the diverse materials had different profiles. Congener 2,3,4,7,8-PeCDF was the one that contributed most to the total I-TEQ concentration for the combustion of cotton, PVC and sludge. This congener has been

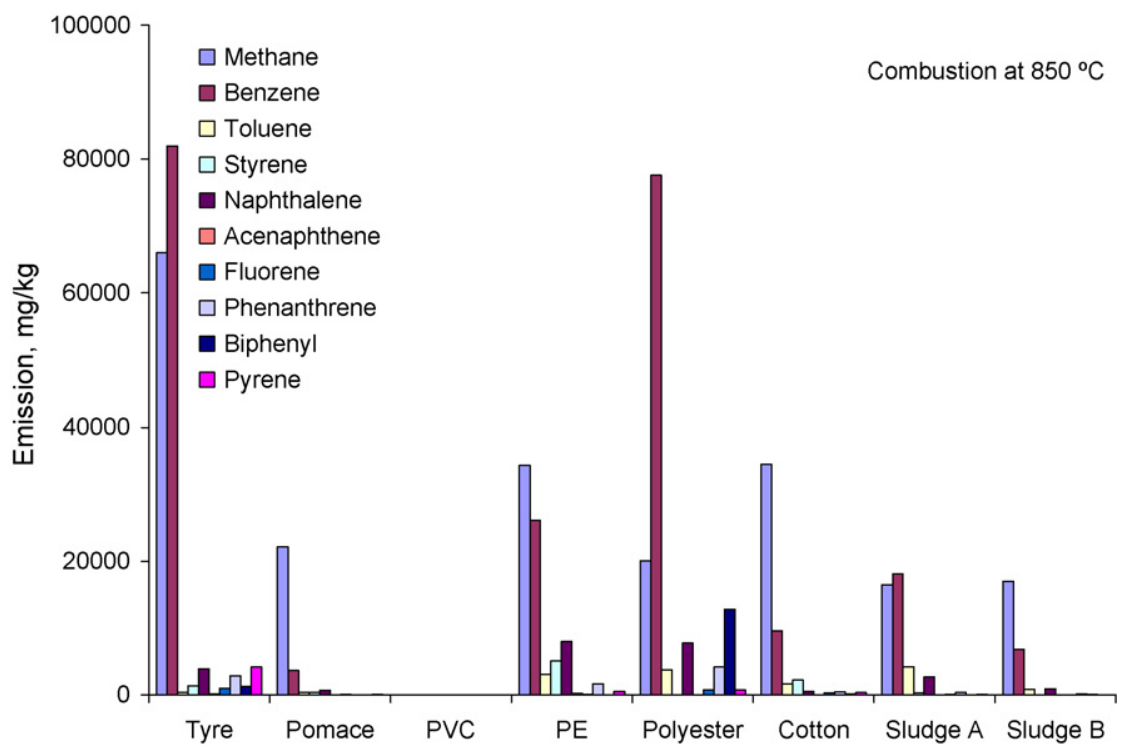

Fig. 3. Emissions of some compounds from combustion at $850{ }^{\circ} \mathrm{C}$ of different wastes. 
Table 3

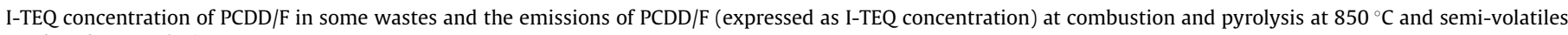
produced at pyrolysis at $850^{\circ} \mathrm{C}$.

\begin{tabular}{|c|c|c|c|c|}
\hline \multirow[b]{2}{*}{ Cotton textiles } & \multirow{2}{*}{$\begin{array}{l}\text { Waste (pg I-TEQ/g) } \\
9.3\end{array}$} & \multicolumn{2}{|c|}{$\begin{array}{l}\text { Combustion at } 850{ }^{\circ} \mathrm{C} \\
\mathrm{CO} /\left(\mathrm{CO}+\mathrm{CO}_{2}\right)(\mathrm{pg} \mathrm{I}-\mathrm{TEQ} / \mathrm{g})\end{array}$} & \multirow{2}{*}{$\begin{array}{l}\begin{array}{l}\text { Pyrolysis at } 850{ }^{\circ} \mathrm{C} \\
\text { (pg I-TEQ/g) }\end{array} \\
\text { Low value }\end{array}$} \\
\hline & & 0.210 & 14.8 & \\
\hline Polyester textiles & 2.7 & 0.106 & 14 & - \\
\hline PVC & 0.6 & 0.092 & 4500 & 215 \\
\hline Sewage sludge A & 5.0 & 0.111 & $1700(1200)$ & 232 \\
\hline Sewage sludge B & 8.1 & 0.079 & 55 & 81 \\
\hline Waste lube oil & 9.5 & 0.457 & 80 & - \\
\hline Meat and bone meals & 0.3 & $<1$ & 40 & 21 \\
\hline Waste paper & 14.8 & $<1$ & 17 & - \\
\hline
\end{tabular}

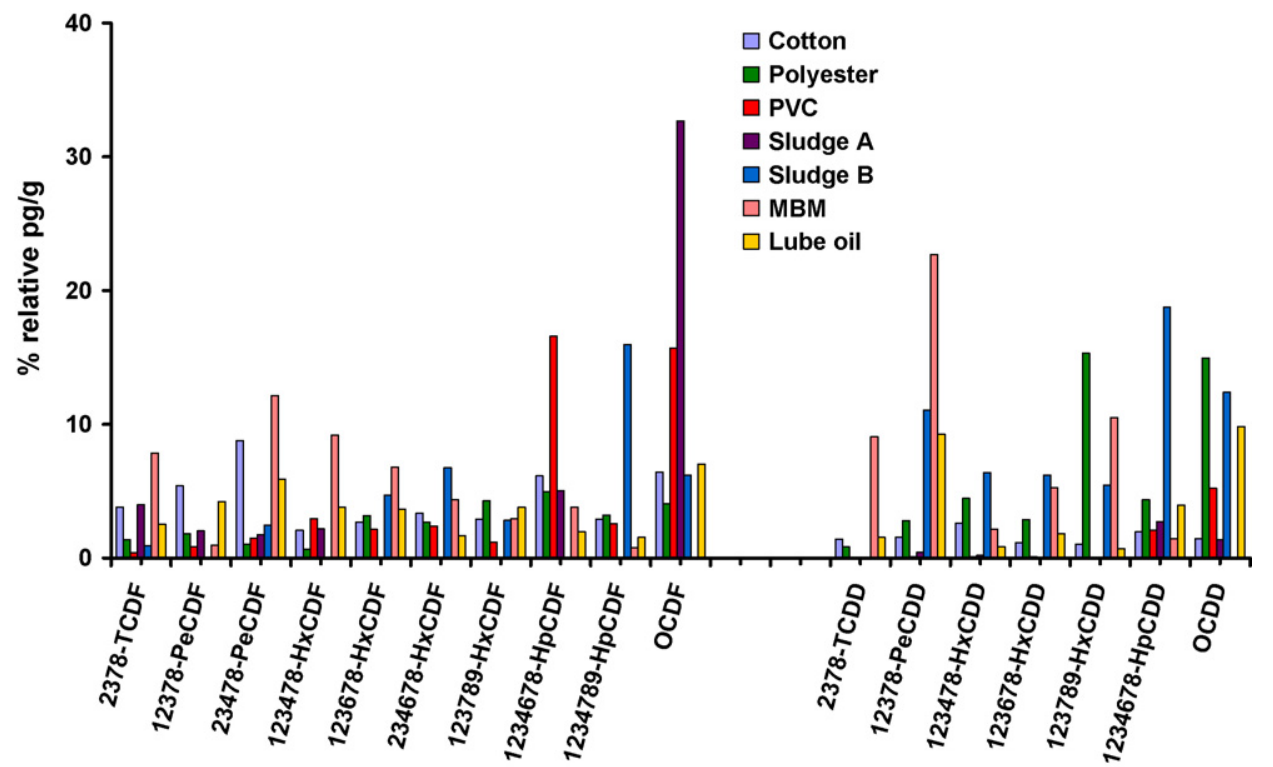

Fig. 4. Comparison of the profile (pg I-TEQ/g) of 2,3,7,8-sustituted PCDD/Fs obtained in the combustion at $850{ }^{\circ} \mathrm{C}$ of different wastes.

found to be the most representative in industrial incinerators [29]. In general, furans contributed more than dioxins to the total toxicity for all wastes, except polyester.

Table 3 also shows the production of PCDD/F in pyrolysis processes. It could be observed that the generation of PCDD/Fs was very small since there was no oxygen present, but the results obtained indicated that formation of these compounds cannot be neglected in pyrolytic conditions. Small amounts of oxygen (poor oxygen atmosphere) could cause a production of such compounds. The obtained results might be explained by: (a) the raw material had initially a significant content of dioxin/furans that could be destroyed at high temperatures, but the pyrolytic compounds obtained could recombine in the low temperature zone to dioxin/ furans, (b) oxidized precursors were formed in the cracking/ formation reactions in pyrolytic conditions not needing more oxygen to form dioxin/furan compounds, and (c) very low content of oxygen present in the inlet stream of nitrogen contributes to the formation of these compounds.

In Figs. 5-7 the distribution of 2,3,7,8-substituted $\mathrm{PCDD} / \mathrm{F}$ congeners (also known as fingerprint) in PVC, meat bone and sewage sludge $B$ is compared with the results from the pyrolysis experiments. There were significant differences between the amount and fingerprints in the raw material and the gas phase collected from the experiments for the PVC and meat bone materials. However, for sludge B, the total concentrations of PCDD/ Fs in the raw material and the yields obtained in the pyrolysis

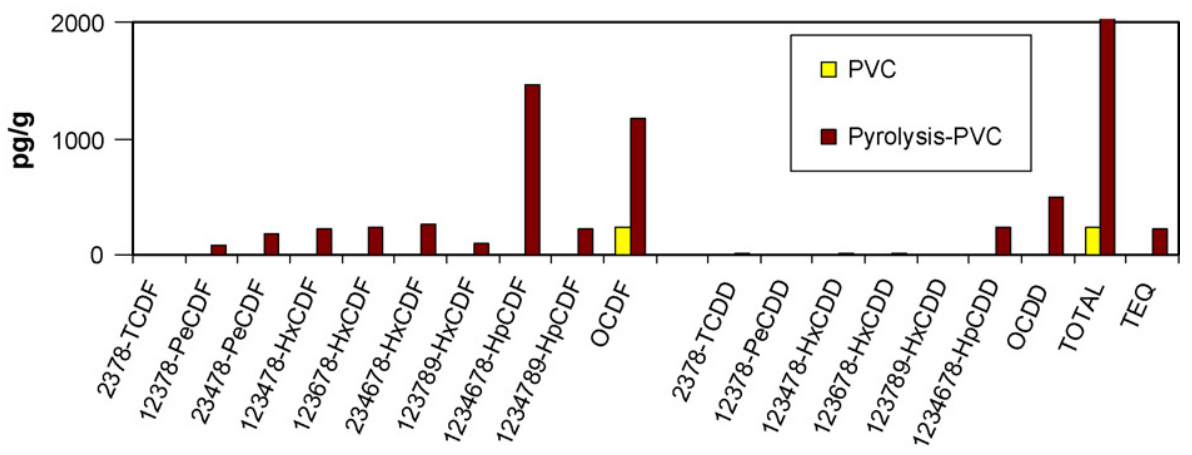

Fig. 5. 2,3,7,8-Substituted PCDD/Fs of PVC (raw material) and emissions produced by pyrolysis at $850{ }^{\circ} \mathrm{C}$. 


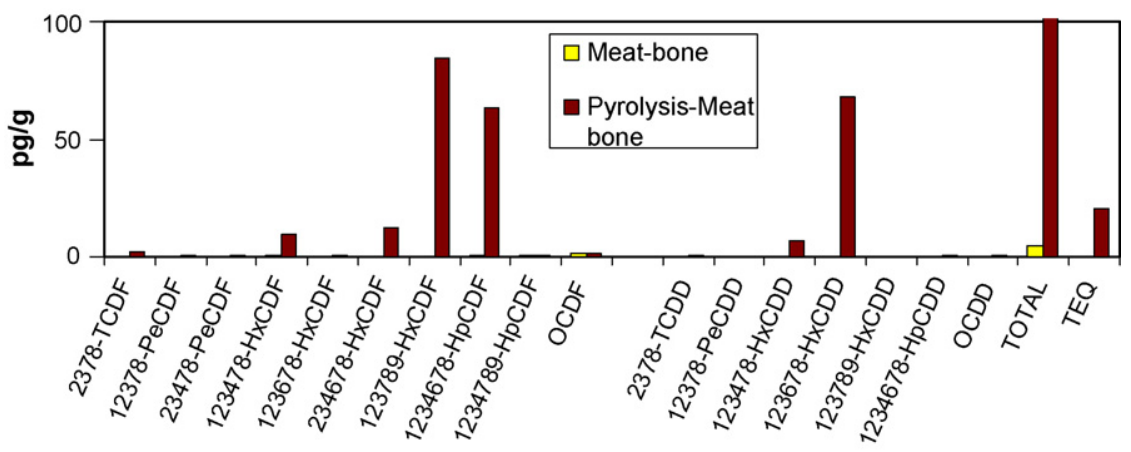

Fig. 6. 2,3,7,8-Substituted PCDD/Fs of meat bone (raw material) and emissions produced by pyrolysis at $850{ }^{\circ} \mathrm{C}$.

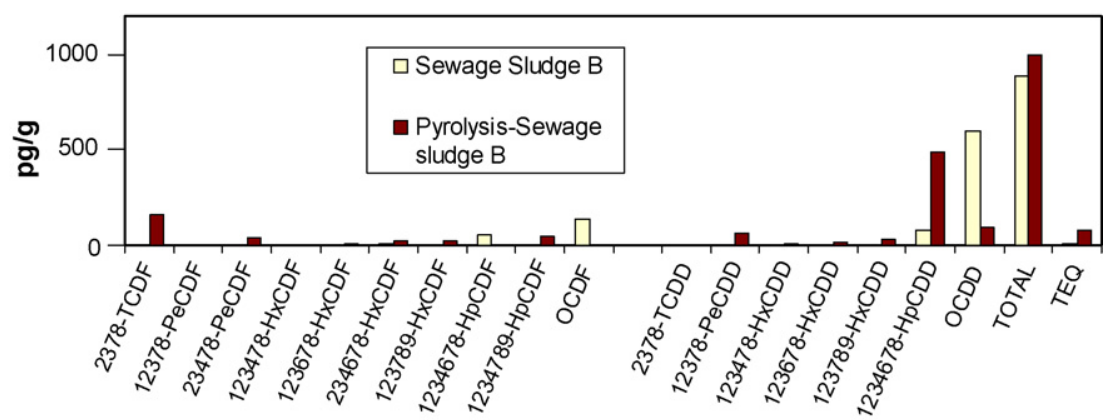

Fig. 7. 2,3,7,8-Substituted PCDD/Fs of sewage sludge B (raw material) and emissions produced by pyrolysis at $850{ }^{\circ} \mathrm{C}$.

experiments were similar, although there was a redistribution of the chlorine atoms that caused the total toxicity TEQ to increase in pyrolysis at $8500^{\circ} \mathrm{C}$.

In a previous study, used polyester fabrics were studied under both pyrolytic and combustion conditions [9] and maximum production of $\mathrm{PCDD} / \mathrm{F}$ occurred between 700 and $800{ }^{\circ} \mathrm{C}$. In this study MBM was investigated in the same manor. Bearing in mind that the reactor is non-isothermal, there is no proof that the PCDD/F formation occurs at this temperature. The maximum total yield is obtained at $700{ }^{\circ} \mathrm{C}$, but the maximum in terms of I-TEQ is produced in the runs performed at $850^{\circ} \mathrm{C}$, due to the dominant presence of $\mathrm{HxCDF}, \mathrm{HxCDD}$ and TCDD. It is known [5] that the production of products of incomplete combustion is higher at $700-900{ }^{\circ} \mathrm{C}$. These compounds react in the post-combustion cooling zone to form PCDD/Fs. At temperatures higher than $950{ }^{\circ} \mathrm{C}$ the I-TEQ decreases drastically to less than $10 \mathrm{pg}$ I-TEQ/g. It has been reported that under lessthan-optimum conditions (such as insufficient oxygen), PCDD/Fs may be formed at temperatures that would normally exceed the threshold temperature of $800{ }^{\circ} \mathrm{C}$ for PCDD/F formation [30,31]. Insufficient oxygen within the furnace frequently leads to the formation of various PAH-type compounds, especially during the phases of devolatilization.

\section{Conclusions}

Both pyrolysis and combustion processes must be controlled from an environmental point of view considering the pollutants, with special attention to PAHs and PCDD/Fs.

From all the studied wastes, a general behaviour was deduced regarding the evolution of semi-volatiles with increasing temperature, both in pyrolysis and combustion conditions. Some compounds decreased with increasing oxygen ratio, mainly volatile hydrocarbons, which were consumed in the presence of oxygen. Oxidized compounds such as alcohols, organic acids, furans and some amides showed a maximum with oxygen present. Some intermediate compounds with a very high resistance to the oxygen in the working conditions present a continuous increase in their concentration when the oxygen ratio increases.

With reference to behaviour versus temperature there were compounds whose yields decreased with increasing temperature, such as some volatile hydrocarbons and semi-volatile compounds. In addition, some pollutants were promoted at intermediate temperatures, e.g. light hydrocarbons, semi-volatile compounds, many monoaromatic compounds and many polyaromatic hydrocarbons.

In a pyrolysis process $\left(850{ }^{\circ} \mathrm{C}\right)$ it was shown that high emission factors or yields of PAHs can be obtained, especially naphthalene, so their formation, retention or presence in the condensate phases must be studied or taken into account.

In a combustion process $\left(850^{\circ} \mathrm{C}\right)$, the evolution of methane, benzene and PAHs, especially naphthalene, are important in order to analyse the operating conditions (oxygen, temperature, residence time and turbulence of the incineration). In this way, the presence of these compounds indicates the formation of puffs with poor oxygen concentration.

The formation of PCDD/Fs is important in both combustion and pyrolysis processes. In pyrolysis, there can be a significant increase of congeners and/or an increase of the total toxicity due to the redistribution of the chlorine atoms to the most toxic congeners. The fingerprint or congener distribution in pyrolysis and combustion at $850{ }^{\circ} \mathrm{C}$, was different for each waste, without a clear trend.

\section{Acknowledgements}

We gratefully acknowledge the financial support from Generalitat Valenciana (Spain) project GV06/069, and the Spanish MCT research project CTQ2005-05262/PPQ. 


\section{References}

[1] M. Dzieciol, J. Trzeszczynski, J. Appl. Polym. Sci. 81 (2001) 3064.

[2] R. Font, I. Aracil, A. Fullana, I. Martin-Gullon, J.A. Conesa, J. Anal. Appl. Pyrolysis 68-69 (2003) 599.

[3] R. Font, I. Aracil, A. Fullana, J.A. Conesa, Chemosphere 57 (2004) 615.

[4] I. Aracil, R. Font, J.A. Conesa, J. Anal. Appl. Pyrolysis 74 (2005) 465.

[5] J.A. Conesa, A. Fullana, R. Font, Chemosphere 59 (2005) 85.

[6] A. Fullana, J.A. Conesa, R. Font, I. Martin-Gullon, J. Anal. Appl. Pyrolysis 68-69 (2003) 561

[7] M.J. Fuentes, R. Font, M.F. Gomez-Rico, I. Martin-Gullon, J. Anal. Appl. Pyrolysis 79 (2007) 215.

[8] J. Molto, R. Font, J.A. Conesa, I. Martin-Gullon, J. Anal. Appl. Pyrolysis 76 (2006) 124.

[9] J. Molto, R. Font, J.A. Conesa, Energy Fuels 20 (2006) 1951.

[10] A. Fullana, R. Font, J.A. Conesa, P. Blasco, Environ. Sci. Technol. 34 (2000) 2092.

[11] J. Jauhiainen, I. Martin-Gullon, J.A. Conesa, R. Font, J. Anal. Appl. Pyrolysis 74 (2005) 512.

[12] M.M. Esperanza, A.N. Garcia, R. Font, J.A. Conesa, J. Anal. Appl. Pyrolysis 52 (1999) 151

[13] A. Gálvez, J.A. Conesa, I. Martín-Gullón, R. Font, Chemosphere 69 (3) (2007) 387.

[14] J.A. Conesa, A. Gálvez, A. Fullana, Chemosphere 72 (2008) 306.

[15] M.F. Gómez-Rico, I. Martin-Gullón, A. Fullana, J.A. Conesa, R.J. Font, Anal. Appl. Pyrolysis 68-69 (2003) 527.
[16] J.A. Conesa, A. Fullana, R. Font, Energy Fuels 14 (2) (2000) 409.

[17] M.F. Gomez-Rico, R. Font, I. Aracil, A. Fullana, Arch. Environ. Contam. Toxicol. 52 (3) (2007) 306.

[18] EPA, SW-846 Test Methods for Evaluating Solid Waste. Physical/Chemical Methods. Enviromental Protection Agency USEPA (available on line).

[19] J. Caponero, J.A.S. Tenorio, Y.A. Levendis, J.B. Carlson, Energy Fuels 18 (2004) 102.

[20] A. Atal, Y.A. Levendis, J. Carlson, Y. Dunayevskiy, P. Vouros, Combust. Flame 110 (1997) 462.

[21] S.K. Durlak, P. Biswas, Environ. Sci. Technol. 32 (1998) 2301.

[22] A.M. Mastral, R. Murillo, M.J. Perez-Surio, M. Callen, Energy Fuels 10 (1996) 941-947.

[23] A.M. Mastral, M. Callen, R. Murillo, T. Garcia, Fuel 77 (1998) 1513.

[24] L. Bonfanti, L. Comellas, J.L. Lliberia, R. Vallhonrat-Matalonga, M. Pich-Santacana, D. Lopez-Pinol, J. Anal. Appl. Pyrolysis 44 (1997) 89.

25] G. McKay, Chem. Eng. J. 86 (2002) 343.

[26] K. Tuppurainen, I. Halonen, P. Ruokojarvi, J. Tarhanen, J. Ruuskanen, Chemosphere 36 (1998) 1493.

[27] B.R. Stanmore, Combust. Flame 136 (2004) 398-427.

[28] E. Abad, K. Martinez, J. Caixach, J. Rivera, Environ. Sci. Technol. 38 (2004) 4734

[29] H. Fiedler, C. Lau, G. Eduljee, Waste Manage. Res. 18 (2000) 283.

[30] B.K. Gullett, K.R. Bruce, L.O. Beach, Waste Manage. Res. 8 (1990) 203.

[31] W.J. Walker, S.L. Huntley, Chemosphere 35 (1997) 1409. 